\title{
Conservation and Flexible Utilization of Lianyungang Cultural Heritages
}

\author{
Wen Jia \\ Lianyungang Normal College, Lianyungang, China \\ Email: 410695438@qq.com
}

How to cite this paper: Jia, W. (2021) Conservation and Flexible Utilization of Lianyungang Cultural Heritages. Open Access Library Journal, 8: e7114.

https://doi.org/10.4236/oalib.1107114

Received: December 27, 2020

Accepted: January 10, 2021

Published: January 13, 2021

Copyright $\odot 2021$ by author(s) and Open Access Library Inc.

This work is licensed under the Creative Commons Attribution International License (CC BY 4.0).

http://creativecommons.org/licenses/by/4.0/

\section{(c) (i) Open Access}

\begin{abstract}
The report of the 19th National Congress of the Communist Party of China pointed out that it is necessary to "strengthen the conservation and utilization of cultural relics and the conservation and inheritance of cultural heritages". Cultural heritages are outstanding relics remaining along the long development history of a country or region condensing the collective wisdom. As a historical and cultural city, Lianyungang must pay attention to the conservation and flexible utilization of the historical culture, so as to add more connotations to the ideas, culture and concepts contained in regional cultural heritages in the new historical period. Therefore, from the aspects of conservation intensity, conservation measures and flexible utilization, this article studied how to promote the creative transformation and innovative development of Lianyungang's outstanding historical and cultural resources in the new era.
\end{abstract}

\section{Subject Areas}

Culture, Politics

\section{Keywords}

Cultural Heritage, Conservation, Flexible Utilization

\section{Introduction}

How to realize the contemporary value of cultural heritages is a common concern throughout China and the world. The role and value of cultural heritages cannot be ignored in any region, because they carry the history of regional development and represent the cultural characteristics of the region, and they can even be regarded as the sign that distinguishes a region from the others. Therefore, the conservation and flexible utilization of cultural heritages are particular- 
ly important. The former focuses more on the preservation of the past, while the latter is for better interpretation and utilization of traditional cultural heritages by effective means on the basis of better preservation, to build a bridge connecting the history and today. On May 11, 2020, when General Secretary Xi Jinping inspected Shanxi, he emphasized that historical and cultural heritages are non-renewable and irreplaceable precious resources, and conservation should always be the top priority. This is an important guiding principle for strengthening the conservation and utilization of cultural heritages and promoting exchanges and mutual learning between different civilizations in different countries and regions. At the same time, it also puts forward higher requirements for strengthening the conservation and flexible utilization of cultural heritage in various regions in the new era. We must pay enough attention to traditional cultural heritages [1].

The conservation of cultural heritages has increasingly become one of the main positions of urban cultural construction. Lianyungang enjoys a long history and culture, advantageous geographical location, excellent cultural environment, and especially abundant cultural heritages with obvious regional characteristics, which has become the most representative cultural symbol of Lianyungang. We can say that these cultural heritages are of great significance and important role for promoting the urban spirit and enhancing the urban image of Lianyungang as the best name card for city publicity. The conservation and flexible utilization of the city's cultural heritages is an effective way to inherit the city's traditional culture and spirit. However, according to the current status of the conservation and flexible utilization of Lianyungang's cultural heritages, there are some problems in the conservation intensity, conservation measures, and flexible utilization methods. It is necessary to further improve the conservation of cultural heritages and innovate the ways and methods of its flexible utilization, to make a name card of the city with profound historical and cultural accumulation [2].

\section{The Current General Situation of Lianyungang Cultural Heritages}

Lianyungang enjoys abundant tangible and intangible cultural heritages. The former includes ancient city relics culture, stone carving culture, architectural culture, transportation culture, and salt industry culture, etc.; the latter includes richer resources with greater influence, in the following forms: 1) Oral instruction and presentation, such as the legend of Xu Fu's Eastward Voyage, the legend of Wuliuhe, and the legend of Filial Woman from the East Sea, etc. 2) Performing arts, such as Haizhou Five Gongs, Huaihai Opera, Tongzi Opera, Northern Jiangsu Qinshu, Northern Jiangsu Liuqin, Fishing Drum, Northern Jiangsu Drum, Wang Qimo Acrobatic Magic, Hong-school Chen-style Taijiquan, Liu-style Ziranquan, Lv Opera and Raced Donkey Dance, etc. 3) Social customs, etiquette and festival ceremonies, such as Lianyungang traditional en- 
tertainment, Gu'an pear production customs, East Sea crystal consumption customs, Haizhou Bay fishermen customs, and Shizu worship, etc. 4) Traditional handicraft skills, such as paper cutting, wood carving, Huai Salt production skills, Li's facial paralysis ointment production skills, Cao's traditional Chinese medicine hot pack osteosynthesis, Banpu sausage making techniques, pancake making techniques, Haizhou rubbing techniques, crystal painting techniques, copper forging techniques, shell sticker painting, Wang Shuyou's drip vinegar brewing skills, and Yunwu Tea making skills, etc.

Currently there are some researches on the cultural heritages in Lianyungang according to the searching results, but actually it is not sufficient, and does not match the proportion to the rich cultural heritages in Lianyungang. It's also hard to provide matching intellectual support for the conservation and utilization of cultural heritages. According to the collected data, it is obvious that the research results mostly focus on the conservation, development and utilization of intangible cultural heritages, and relatively few are on tangible cultural heritages. At present, the specific research papers on tangible cultural heritages included by CNKI are only the Architectural Characteristics and Distribution of the Modern Catholic Churches in Lianyungang, the Establishment and Framework Conception of Lianyungang Yuntai Mountain Regional Cultural and Ecological Reserve, the Conservation and Public Cognition of Rock Arts-Jiangjunyan Rock Arts as an example, as well as the Conservation and Renewal of Ancient Lianyun Historical and Cultural City in Lianyungang, the Conservation of Ancient Haizhou Cultural City and some other articles. The others are only extensive researches based on "the mountain and sea culture". No more paper data involves the conservation and utilization of material cultural heritages. It indicates that the current research on tangible cultural heritages in Lianyungang is not ideal. Even for intangible cultural heritages with relatively rich resources, the quantity and quality are not optimistic according to the current situation that can be searched in major databases. Most researches focus on the macroscopic level, and the microscopic researches are basically on the Journey to the West Culture, the Flowers in the Mirror Culture, Xu Fu Culture, Haizhou Five Gongs and Huaihai Opera. There are very few or almost no other research results on intangible cultural heritages. Comparing with the quantity of intangible cultural heritage projects listed on Lianyungang Intangible Heritage Network, there is still much room for research. Moreover, the above-mentioned research results mostly focus on the importance, historical and cultural value, and the current status of inheritance of cultural heritages, and few involves the research on the flexible utilization of cultural heritages, and especially the research materials are in lack on how to realize the conservation and utilization of cultural heritages at a higher level with more value of the times by new technological methods, such as VR and AI technology. It is precisely the focus of the current researches on the flexible utilization of cultural heritages, and the key field to be explored on the conservation and flexible utilization of cultural heritages in Lianyungang [3]. 


\section{Ways of Conservation and Flexible Utilization of Lianyungang Cultural Heritages}

The report of the 19th National Congress of the Communist Party of China stated that: "Culture is the soul of a country and a nation. Prosperous culture brings about prosperous country and strong nation. Without a high degree of cultural self-confidence, and cultural prosperity, there would be no great rejuvenation of the Chinese nation." It indicates that the value of culture for a country is extraordinary and cannot be ignored. Similarly, for a city, abundant and vivid local cultural heritages with unique regional and special properties must be well protected and effectively innovated and used. Only in this way can the city develop and thrive.

As mentioned above, due to the complex system of Lianyungang cultural heritages, the current conservation and flexible utilization is not sufficient. The conservation and utilization of cultural heritages is a hard and long-lasting task. It is impossible to achieve the expected results overnight. Therefore, the conservation and flexible utilization of Lianyungang cultural heritages must follow the objective laws, and depend on multi-party joint efforts guided by the government to establish a scientific, efficient, and sustainable conservation, development and utilization mechanism. Only in this way can the greatest value of precious cultural heritage resources in Lianyungang be actually realized, to display their new charm and value in the new era, serve the cultural construction of the city, and make a unique cultural name card for building the city of "high-quality development" [4].

First, locate and make up the deficiencies, and strengthen professional and normative researches. The standardization process of cultural heritages in Lianyungang started late, resulting in some problems in the heritage investigation and classification. No detailed standards exist regarding the assessment, classification, and protection of cultural heritage. The related work is proceeding slowly, which is negative for the timely and sufficient protection of the cultural heritages. It needs the relevant departments to make up the deficiencies, establish a long-term and systematic tracking system, and realize full coverage of the conservation system. As mentioned above, Lianyungang has very few research results on cultural heritages. The researches are not in-depth enough, and especially the researches on tangible cultural heritages are not ideal in both quantity and quality, which is even more insufficient comparing with the conservation of intangible cultural heritages. It's necessary to take the conservation of tangible cultural heritages as the key job of Lianyungang every year. Relevant departments should lead to formulate relevant conservation policies and make overall planning. At the same time, they should invite experts from all over the city, the province, and even China in related fields to offer professional, standardized, and advanced construction advices and suggestions for the conservation of Lianyungang tangible cultural heritages. Practical problems in the researches on Lianyungang intangible cultural heritages should also be focused. That is to say, 
the research results are in lack of microscopic exploration with more practical value, and most focus on folk literature, traditional music, and traditional drama. There are few or even no research result in other areas. This indicates that the researches on intangible cultural heritages need to take different conservation measures according to different situations of intangible cultural heritages based on sufficient investigations, and especially put emphasis on strengthening the conservation and research in blank areas [5].

In particular, it is necessary to mobilize the scientific research institutes and universities all over the city to take their advantages in scientific research, to make reasonable and orderly classification, special investigations, and detailed researches on the cultural heritages, so as to fully develop their potentials, and explore the application of information technologies and other emerging methods in the development and utilization of cultural heritages on the basis of scientific and detailed researches, so as to achieve a win-win result in both conservation and utilization. In particular, colleges and universities have obvious advantages in talent, which is very beneficial for better conservation, development and utilization of cultural heritages. We should mobilize university teachers, especially those in humanistic fields. We should strengthen the cooperation between personnel and departments, make joint efforts to well organize the conservation, development and utilization of Lianyungang cultural heritages by integrating resources and improving mechanisms, integrate the researches on cultural heritages and the construction of college curriculum system, and encourage teachers in the fields of humanities and social sciences to actively apply for the research subjects related to the conservation, development and utilization of municipal cultural heritages, write related papers or monographs, increase related scientific research output based on the actual situation of the city, and put the scientific research results into practical application in time, to form an effective integration of teaching, research and social radiation.

Second, make joint efforts and take multiple measures to strengthen conservation. In recent years, Lianyungang cultural heritage conservation and inheritance has made some achievements in terms of conservation intensity and conservation measures, which improved Lianyungang's urban image. At the same time, we must also realize that there is still much development space in the conservation and utilization of cultural heritages. Only by making joint efforts and taking multiple measures simultaneously can we make more detailed and complete conservation, development and utilization of Lianyungang cultural heritages.

Considering wide distribution, complicated situation, and unbalanced conservation and utilization of Lianyungang cultural heritages, the municipal government should lead various departments and channels including culture, publicity, education and technology to jointly establish cultural heritage conservation and utilization mechanism, and jointly carry out the conservation, development and utilization of the municipal cultural heritages, so as to form a good state of wide coverage and lasting measures, and achieve cross-regional integra- 
tion of cultural heritage conservation, development, and innovative utilization among the municipal districts and the other three counties. We should connect cultural heritage resources into lines, areas, and even networks, to take advantage of the "integration effect" and form a joint force for conservation, development and utilization. At the same time, through the integration, we can achieve sharing and complementation of advantageous cultural heritage resources between different regions. In this process, various departments should pay special attention to communication, and integrate the development forces of education, publicity, cultural relics conservation and tourism in the implementation of specific policies, and establish a four-in-one construction platform integrating policy guidance, scientific research, publicity and education, and innovative utilization all over the city, to provide institutional guarantees, material foundations and intellectual supports for the conservation and development of Lianyungang cultural heritages.

Therefore, the government must strengthen management, formulate targeted and operational guidelines and policies to strengthen the conservation of Lianyungang cultural heritages and promote its innovative utilization. At the same time, we should establish a long-term monitoring and management mechanism for the actual implementation of above-mentioned measures to ensure practical effect of cultural heritage conservation and utilization. On the basis of strong and effective conservation, we should strengthen the publicity of cultural heritage conservation all over the city, and especially improve the social cognition and expand the influence of cultural heritages by methods of AI, VR technologies and emerging media; secondly, we should strengthen the sense of responsibility of the whole society for cultural heritage conservation, strengthen the popularization of relevant laws and regulations to all people on the basis of strengthening education to achieve legal conservation. Especially, we should strengthen the popularization and education of relevant laws and regulations aiming at students and this age group in the city. We can expand the scope of law popularization and deepen legal education by virtue of class meetings and League member activities, and radiate it from this point to the whole city, to strengthen the cultivation of the cultural heritage conservation awareness of the whole society, and improve the cultural heritage conservation capability of all people; thirdly, we should increase the investment in cultural heritage conservation, set up special funds in municipal budget every year to invest in cultural heritage conservation, and at the same time cultivate and found a talent team with high working ability and professional quality to provide strong talent and intellectual supports for the conservation of Lianyungang cultural heritages.

The specific technical operations can depend on 716, China Telecom and other units to monitor all the tangible cultural heritages in the city in an all-round and all-time way through Internet communication infrastructure and wireless networks, to prevent natural and man-made losses; we can follow the conservation measures of Dunhuang Mogao Grottoes, to repair and replicate the physical 
heritages by three-dimensional modeling, holographic photography and other methods, which can display the cultural heritages in digital method on the basis of preservation; at the same time, we should build abundant data bases of intangible culture heritages by modern information technological methods, publicize and promote it to the whole city depending on the website of Lianyungang Intangible Heritage, and regularly organize relevant cultural activities in all districts and counties of the city to enhance the popularity and reputation of all intangible cultural heritages, and especially to improve the publicity and conservation of unpopular intangible cultural heritages. We should promote in-depth development of Lianyungang intangible cultural heritage conservation by various means, and gradually transform the only governmental and professional organization actions into spontaneous non-governmental actions.

Third, efficient integration, to promote flexible utilization of cultural heritage

Cultural heritages are mostly far from our real life due to its historical nature. This is also one of the bottlenecks in the process of conservation. Therefore, the conservation of cultural heritages must be based on its flexible utilization. We must reduce this problem through innovative utilization, so that cultural heritages are not only accumulated history, but also closely related to people's daily life in the new era and become a part of our ordinary life. In this way, cultural heritages can reflect new vitality and in turn actively promote cultural heritage conservation.

We should actively explore to promote the industrialization of cultural heritage conservation and utilization through high-degree integration with other industries and other fields. We can vigorously develop the cultural and creative cultural heritage products related to "Journey to the West Culture", "Flower in the Mirror Culture", "Xu Fu Culture" and revolutionary cultural resources taking advantage of the influences of natural landscape, literary works, and music and art works, etc., design cultural heritage-related products that are very popular in market and easy to circulate and sell, make a series of products with long-term promotion value in different types, and sell them in the flagship stores for theme product sales on various e-commerce platforms to expand market cognition and then promote the influences of Lianyungang cultural heritages.

At the same time, we should further expand the domestic and international influence of the Lianyungang Cultural Tourism Festival, design more highly operable and popularized cultural products and launch them in the tourism festival. We should focus on the construction of cultural relics and museum product stores in key scenic areas and popular business circles, build a number of compact, exquisite and stylish mobile vendors in distinctive appearance with regional cultural characteristics of Lianyungang, and mostly launch them in the peak season of tourism in Lianyungang, to promote the sales of cultural relics and museum products depending on the tourism industry, form a good situation integrating tourism, popularity and cultural heritage conservation and utilization, and at the same time ensure the funds for cultural heritage conservation.

We can broaden the spread of cultural heritages and especially intangible cul- 
tural heritages in virtue of Lianyungang's advantageous position in the construction of "the Belt and Road", and organically integrate the resource development of "the Belt and Road" with the conservation and flexible utilization of cultural heritages, to promote Lianyungang cultural heritages to go global and thrive. Although cultural heritages are obviously regional, the promotion of cultural exchanges between regions and countries in various forms will inevitably promote better development and utilization of cultural heritages. Since ancient times, culture and cultural products have been an important medium for the communication between various countries. The reason why Chinese civilization remained the continuous context along thousands of years is that we have attached great importance to cultural exchanges and continuously introduced and output culture. We can never ignore the important value of cultural products in this respect in any stage of historical development. Today, China is in a period of rapid development in the new era. Lianyungang, as the east bridgehead of the Eurasian Continental Bridge, should fully understand the great promotion value of its own cultural heritages, seize the development opportunities, and try to narrow the distance with other cities in China and other foreign trading partners, and expand the circle of friends through the cultural heritages and derivative products in the process of foreign trade and foreign exchanges.

\section{Conclusion}

The proper attitude towards cultural heritages is not simply discovery and conservation, but more importantly, we need to fully explore their value on the basis of inheritance, organically integrate conservation and flexible utilization and pursue innovative development. Only in this way can we constantly promote Lianyungang cultural heritages to make new advances and innovations in the integration and transformation of traditional values and modern concepts, and can cultural heritages realize their great cultural value in the new era. Therefore, now the proper attitude towards cultural heritages of Lianyungang is to excavate the historical and practical value of abundant cultural heritages in Lianyungang and innovate the means of flexible utilization of cultural heritages by virtue of new technologies and methods, on the premise of adhering to taking conservation as the first principle, so as to achieve a win-win situation in conservation, development and utilization.

\section{Acknowledgements}

The author thanks the support of 2020 Lianyungang application research: Promote the Researches on Conservation and Flexible Utilization of the City's Cultural Heritages (SLYZ204008).

\section{Conflicts of Interest}

The author declares no conflicts of interest regarding the publication of this paper. 


\section{References}

[1] Xi, J. (2017) Secure a Decisive Victory in Building a Moderately Prosperous Society in All Respects and Strive for the Great Success of Socialism with Chinese Characteristics for a New Era. Report at the 19th National Congress of the Communist Party of China (October 18, 2017), People's Publishing House, Beijing.

[2] Du, S. (2019) Our Understanding of Time (Focus on President Xi Jinping's Visit in Europe). People's Daily Overseas Edition, 26 March 2019, 2nd Edition.

[3] Cui, F., Li, M. and Shen, Z. (2014) The Influence of Economic and social Development on the Cultural Heritage Protection of Sea-Island Agricultural Settlements-A Case Study of Xilian Island Village in Lianyungang. Chinese History of Agriculture, 33, 123-131.

[4] Liu, J., Sun, Y., Yun, M., Liu, Z. and Zhao, X. (2012) On the Protection and Rescue of Important Regional Geological Heritage in Lianyungang-Based on the Perspective of Fossil Discovery of Ancient Whale Bones. Journal of Huaihai Institute of Technology (Humanities and Social Sciences Edition), 10, 87-89.

[5] Zhao, M. (2011) SWOT Analysis of Lianyungang Shanhai Cultural Ecological Protection Experimental Area. Journal of Huaihai Institute of Technology (Humanities and Social Sciences Edition), 9, 19-23. 